\title{
ESTRATEGIAS ESPACIALES DE COMICIDAD EN LA COMEDIA DE CAPA Y ESPADA CALDERONIANA ${ }^{1}$
}

\author{
Romina Irene Palacios Espinoza \\ Universität Wien \\ Facultad de Estudios Filológicos y Culturales \\ Austria \\ roirpaes@gmail.com
}

¿Cómo se provoca el enredo en la comedia cómica mediante el escondite del galán o de la dama, el ocultamiento tras un elemento arquitectónico-decorativo, los traspasos de los personajes de espacios patentes a latentes o la transgresión funcional de ambientes establecidos?

Alrededor de esta interrogante se concentra la presente contribución, para lo cual se pondrá énfasis sobre el tratamiento espacial en la construcción del enredo y se indicará cómo dicha intriga suscita la reacción en el espectador, esta traducida en la risa ${ }^{2}$ o en sus variantes graduales. Este análisis no pretende insinuar que el regocijo del público

${ }^{1}$ Este trabajo forma parte del proyecto de investigación Secrets and secrecy in Calderón's Comedies and in Spanish Golden Age Culture, dirigido por el Dr. Wolfram Aichinger y financiado por el Austrian Science Fund FWF (project number P24903-G23) y el Anniversary Fund del Oesterreichische Nationalbank (project number 14725).

${ }^{2}$ En relación con la risa a modo de manifestación receptiva lograda a través de mecanismos dramatúrgicos puestos en escena considero relevante la opinión de Sandro Barros. Aunque tal opinión es expresada a raíz de la novela y la discreción cervantina, aparece de manera análoga el desarrollo de la risa tras la captación de las estrategias que provocan su expresión en la comedia cómica calderoniana. «Una vez que su significado [del humor dentro de la novela] es asimilado por el lector, la risa cede espacio a una cadena de ecos cómicos, reforzados por peripecias y movimientos autoriales inesperados 
se debe exclusivamente al empleo de los espacios a manera de estrategias, puesto que es indiscutible que la destreza de Calderón se halla no solo en la hábil utilización de los grados de representación espacial sino también en los diversos y heterogéneos recursos con los que construye tácticas diseñadas para el entretenimiento del auditorio ${ }^{3}$.

La comicidad y el elemento lúdico que conducen las directrices del argumento de las comedias actúan a modo de una simbiosis en la construcción de un producto complejo y heterogéneo, pese a que se cuente con elementos intertextuales reconocibles, cuyas conexiones no se limitan a ciertas obras del corpus calderoniano, sino que se remiten a diversas creaciones de la producción literaria áurea en general.

La simbiosis referida, es decir, la asociación de lo cómico y lo lúdico en el argumento dramático encauza sus atributos hacia la respuesta del espectador, puesto que tanto emisor como receptor se confabulan durante el transcurso de la función teatral ${ }^{4}$.

A esta complicidad ${ }^{5}$, esencial en todo tipo de puesta en escena y requisito evidente de toda clase de comicidad, es a la que se apelará. Se verá así el juego y acercamiento entre emisor y receptor, que implica en este caso concreto el uso espacial y de elementos arquitectónicos, los

a lo largo de la obra, que aquí he caracterizado esencialmente como lúdicos» (Barros, 2006).

${ }^{3}$ Otras estrategias dirigidas al divertimento en la comedia áurea en general y en la obra de Calderón en particular son los intercambios de vestuarios, los equívocos, el empleo estereotipado de formas dialectales, la autoburla, las gesticulaciones, etc.

${ }^{4}$ La confabulación entre el emisor y el receptor es expuesta por Charles Mauron del modo siguiente «El espectador está rápidamente advertido de que participa mentalmente en un juego [...] El autor cómico se aprovecha de esto sin tardanza» (Mauron, 1998, p. 29). Rosana Llanos López, siguiendo la pauta de Mauron, expone su opinión sobre este asunto: «observar el fin que se persigue o el efecto que se busca suscitar, entendido éste no sólo como la reacción que la obra produce en el espectador, sino también como el proceso de construcción de este efecto por parte del autor, ya sea consciente o inconscientemente» (Llanos López, 2004, p. 1170). Para mayores detalles sobre este aspecto, ver también Rosana Llanos L, 2005.

${ }^{5}$ Con respecto a esta complicidad señala Francisco Ruiz Ramón: «Gracias a esa dinámica relación entre la imaginación del público, el espacio escénico y el juego de los actores, la acción dramática y su representación escénica fluyen sin interrupción llevando al espectador de los corrales de la plaza del pueblo al salón del trono (Fuenteovejuna), de la torre en el monte al palacio real (La vida es sueño), del cuarto y la cama de la duquesa en Nápoles a la de Tisbea en la playa de Tarragona (El burlador de Sevilla), pero también de los espacios interiores del deseo o del sueño a los laberintos del instinto y de la imaginación o del entendimiento» (Ruiz Ramón, 2000, p. 19). 
cuales posibilitan la creación de una respuesta cómica, mediata e inmediata, en el espectador.

\section{Apunte CONCEPTUAL}

Los espacios de representación de la producción teatral del Siglo de Oro y con aguda resonancia aquellos de la comedia calderoniana han sido ampliamente abordados en diversos estudios que destacan su función escenográfica, simbólica y metafórica. Estos trabajos concuerdan en reconocerlos como elemento vertebral y cómplice en la construcción de la intriga. Es así que se presenta de manera clara la versatilidad, multiplicidad y sobre todo, la permeabilidad de los elementos arquitectónicos dispuestos en el argumento, de los cuales se beneficia el teatro al dirigir una suerte de manipulación de estos referentes espaciales ${ }^{6}$.

El dramaturgo enajena ambientes y elementos arquitectónicos concretos de su función primigenia como referentes de identificación de los lugares de acción. El proceso de enajenación concede así la adaptación del entorno a un preciso momento, a una determinada acción o a un personaje específico en provecho de la representación, lo que adiciona propiedades que confluyen en la creación de la intriga, el juego entre emisor y receptor, y la reacción del espectador ${ }^{7}$.

Ahora se concentrará la observación sobre las estrategias espaciales de un conciso repertorio de comedias cómicas calderonianas. Para la selección de este corpus han sido considerados dos tipos de filtros. Primero, la comedia debe responder al subgénero de las de capa y espa$\mathrm{da}$, pues en estas comedias se reconocen la preponderancia del ambiente urbano y la relevante alternancia entre cuadros interiores y exteriores ${ }^{8}$.

\footnotetext{
${ }^{6}$ Se cuenta con una amplia gama de estudios sobre el espacio y su carácter prismático en la comedia del Siglo de Oro. Son fundamentales los trabajos deVitse, 1996; Ruano de la Haza, 2001; Cazal, González y Vitse, 2002; Rubiera, 2005.

${ }^{7}$ Charles Mauron indica como criterio determinante para la diferenciación de la tragedia y la comedia «la naturaleza de las reacciones psicológicas que el autor se propone suscitar en el espectador» (Mauron, 1998, p. 12). El autor concluye que «la definición central en el género cómico sería el hacer reír al espectador en las condiciones y por los medios propios del teatro" (Mauron, 1998, p. 13).

${ }^{8}$ Stefano Arata hace hincapié sobre la evidente expansión del protagonismo de los ambientes interiores sobre los exteriores. De este modo se aprecia de manera sugerente que los cuadros interiores en las comedias La dama duende y Casa con dos puertas, mala es de guardar ocupan el 76\% y 75\% del total de los versos (ver Arata, 2002, p. 201).
} 
Segundo, el enredo debe ser el producto de un conflicto incongruente del empleo espacial, lo que influye en el sistema inicial de la representación y consigue la superación de la expectativa del público. Para esta ocasión y conforme a estos criterios se han seleccionado las comedias El hombre pobre todo es trazas, Mejor está que estaba, También hay duelo en las damas y El escondido y la tapada. A partir de ellas serán expuestos algunos momentos clasificados en tres tipos de estrategias que contemplan la función espacial orientada a la comicidad'.

Estrategia de comicidad basada en la descripción de espacios y su reflexión

En este sentido se hace referencia a aquellos lugares cuya representación no es necesariamente visible, sino que más bien se configura a través de la palabra y se concreta en la imaginación del espectador. Es decir, estos pueden formar parte no solo del espacio patente sino también del latente ${ }^{10}$.

$\mathrm{Su}$ descripción, en muchos casos a modo de reflexión, revela cierta exageración o ironía, que apela al conocimiento del lugar por el espectador y al entendimiento del porqué del empleo de rasgos altisonantes al momento de su exposición. El tono hiperbólico, cómico e irónico en dicha descripción suele presentarse como guiño hacia el espectador para provocar su regocijo.

Por ejemplo en El hombre pobre todo es trazas, la entrada en Madrid de Rodrigo y su recibimiento por parte de don Diego denotan cierto

${ }^{9}$ Es claro que para lograr esto es condicional una relación de complicidad entre autor y receptor, encontrándose este último familiarizado con los códigos pautados por el dramaturgo y expuestos en escena. Una idea de Henry Bergson expuesta en La risa. Ensayo sobre el significado de la comicidad confirma el vínculo cómplice y necesario para que la risa sea suscitada: «La risa esconde una segunda intención de entendimiento, e incluso de complicidad, con otras personas que ríen, reales o imaginarias» (Bergson, 2011, p. 12).

${ }^{10}$ La definición del espacio en el teatro varía según el ángulo de su observación. Si se analiza el espacio a través de los planos de su representación, tenemos a los patentes, latentes y ausentes. A partir de la interacción de los personajes en escena y la complejidad de la acción se han determinado otro tipo de configuraciones espaciales como las itinerantes, lúdicas, etc. En relación con la multiplicidad espacial y los grados de representación de las acciones en la comedia calderoniana, ver Bobes Naves, 1997, pp. 404-406; García Barrientos, 2003 y 2007, pp. 11-40; Rubiera, 2005. 
aire de confusión, cuando aquel se queja de la dificultad que ha tenido al buscar la dirección de su amigo.

$\begin{array}{ll}\text { Don Diego } & \begin{array}{l}\text { Tú seas tan bien venido } \\ \text { como has sido deseado. }\end{array} \\ \text { Rodrigo } & \text { Tú seas tan bien hallado } \\ & \text { como bien buscado has sido; } \\ \text { que ha tres horas que llegué } & \text { y tres mil que ando buscando } \\ \text { esta posada. }\end{array}$

Don Diego

Pues, cuando te escribí, ¿no te avisé de la calle?

RODRIGO

$\quad$ ¿Lindo talle!
En Madrid ¿no es cosa llana,
señor, que de hoy a mañana
suele perderse una calle?
Porque, según cada día
se hacen nuevas, imagino
que desconoce un vecino
hoy adonde ayer vivía.

(El hombre pobre todo es trazas, p. 653)

Los versos de Rodrigo manifiestan cierta exageración frente a la confusión e incomodidad al haber buscado durante mucho tiempo la residencia de don Diego. El grado exagerado en el parlamento de Rodrigo posee un carácter cómico a modo de alusión lúdica hacia el espectador. Esta cómplice insinuación contiene un indicador social de conocimiento contemporáneo, lo que soporta la cercanía del público al juego tramado sobre las tablas.

Este parlamento da las pautas para crear en la imaginación del espectador la gráfica de Madrid, ciudad que crece desmesuradamente y que hace alusión a un nido de confusiones, lo que construye a su vez un lugar favorable para las tretas del mujeriego don Diego. Esta insinuación se confirma en las palabras con que don Diego expresa con desorbitante afán el encanto hacia su nueva residencia, comparando así Madrid con Babilonia, «donde verás confundir / en variedades y lenguas / el ingenio más sutil» (Calderón de la Barca, El hombre pobre todo es trazas, p. 655). 
En esta misma comedia aparece de manera similar en la jornada tercera la descripción de un ambiente cuyo tinte cómico se basa en referencias metaliterarias ${ }^{11}$. Se vuelve a requerir la introducción de la palabra para completar su concepción visual en la imaginación del espectador y así se produce la carcajada en el público.

En un cuadro exterior, Beatriz, Clara y sus respectivas criadas, Inés e Isabel, pasean por las cercanías de la iglesia de San Jerónimo. Al advertir la llegada inesperada de los galanes, las damas deciden esconderse.

BeAtriz

Lo mejor es escondernos

detrás destas rotas tapias.

Vanse las dos damas.

INÉS

Estéril poeta es este,

pues en un campo le falta

murta, jazmín o arrayán

para esconder unas damas.

ISABEL ¿ ¿No ves que estamos detrás

de san Jerónimo y basta

que finja tapias? Y aun esas

plegue al cielo que las haya.

(El hombre pobre todo es trazas, p. 731)

Ambos ejemplos muestran cómo ayuda la palabra a completar la construcción visual del entorno en la imaginación del espectador y cómo su descripción demanda la participación de su receptor para así comprender su maniobra cómica. Ignacio Arellano indica al respecto que la calidad visual de la palabra hace que el espectador sea convencido de la «apariencia» de algo, sea esto un personaje o un espacio, mediante «la ponderación verbal que dirige psicológicamente la percepción visual» ${ }^{12}$.

11 Jesús Sepúlveda señala en relación con El escondido y la tapada el mecanismo de insertar esporádicamente en los diálogos menciones sobre el mundo del teatro. Este artificio del dramaturgo (el cual es común denominador de la comedia áurea en general) aparte de romper la ilusión escénica, aspecto indicado por Felipe Pedraza, también funciona a manera de recordatorio para el público del carácter convencional del subgénero, lo que conlleva un alto grado de comicidad y se constituye al convertirse en un elemento más del cliché representado en escena (ver Sepúlveda, 2003, p. 818 y Pedraza, 2000, p. 202).

${ }^{12}$ Ver Arellano, 1995, p. 418. 
De este modo y a pesar de las limitaciones espaciales del escenario que llegan a ser resueltas mediante el empleo de diversos recursos, la palabra sirve de apoyo para que el entorno sea ampliado y aderezado, convirtiéndolo así en instrumento de comicidad ${ }^{13}$.

\section{Espacios de intervención espontánea}

La participación de este tipo de estrategia fomenta la creación de enredos, aunque aporte cierto grado de incoherencia debido al extremo oportunismo o casualidad de su presencia en la trama. Sin embargo, ya sean estos embrollos representados de manera visible o descritos mediante los versos de un personaje, son necesarios para sentar las bases de la intriga puesta en escena a través del juego de alianzas y enfrentamientos entre los actores. Al ser estos descritos y no puestos en escena, la palabra dirige la atención del espectador a un ambiente o elemento arquitectónico, el cual podría haber pasado desapercibido en primera instancia. Dicha intervención, acentuada por la mención explícita de su representación en escena, indica la alteración espacial en ventaja del ardid escénico. En palabras de Arellano, «el objeto sería invisible sin la activación verbal» ${ }^{14}$.

La recepción de estas situaciones es captada bajo el velo de lo espontáneo y lo fortuito. En este sentido, el dramaturgo manipula el pacto que ha creado con el espectador para así exponer sobre el tablado episodios que superan la expectativa del público. Empero, una segunda complicidad se crea, pues ante la desbaratada expectativa y la aparición de elementos espaciales que lindan con la casualidad, el nuevo "orden» de las acciones será aceptado por el público verosímilmente en favor del eco lúdico que requieren los enredos ${ }^{15}$. El protagonismo de estos

${ }^{13}$ Un panorama más extenso y detallado sobre la función de la palabra en la construcción visual de la escena es ofrecido por Ignacio Arellano, 1995. Arellano expone que «la función complementaria o sustituyente de la palabra tiene que ponerse en práctica cada vez que algo sea imposible de representar a la vista, bien por razones técnicas (entonces se suele recurrir al decorado verbal y a la ticoscopia), bien por razones éticas, de decencia moral: en el teatro anterior al Barroco ciertas escenas truculentas, sangrientas o lastimosas se escamoteaban a la vista sustituyéndolas por una narración o una descripción ticoscópica» (Arellano, 1995, p. 418).

${ }^{14}$ Arellano, 1995, p. 419.

15 «[El teatro] comparte con el juego infantil su poder de transportarnos fácilmente con la imaginación a otros lugares y a otros tiempos y de transformar cuatro tablas en un 
elementos arquitectónicos que se presentan a modo de símbolos de los lugares en donde se ubican, motiva la complejidad de los enredos y ayuda a alcanzar de manera progresiva el ápice de comicidad perceptible en los siguientes ejemplos.

El asesinato o la lesión del contrincante suele ser desenlace de un duelo acalorado entre caballeros, pero asimismo es punto de partida de muchos enredos en la comedia de capa y espada. Esta pendencia obliga al galán, defensor de su honor, a huir y buscar refugio, llegando incluso a irrumpir en casa ajena.

Es de este modo que don Carlos Colona, el galán en Mejor está que estaba, tras una riña sale al escenario, este representado por la sala en casa de don César y su hija Flora. Se supone que después de matar a su contrincante huye don Carlos y al ver la puerta abierta de la casa de doña Flora, infringe las leyes de hospitalidad y se convierte así en huésped fortuito. Al ser perseguido don Carlos por don Arnaldo y Celio, el galán recurre a la ayuda de Flora para que esta disponga de una guarida para el prófugo.

Sale don Carlos con la espada desnuda.

Carlos Si en la hermosura

hay piedad, y hoy no se implican

piedad y hermosura, puesto

que siempre son enemigas, vuestro sagrado le valga, oh, señoras, a una vida, contra quien hoy de los hados se han conjurado las iras.

[...]

FLORA No prosigas, que a mí me toca ampararle.

Cúbrete desta cortina.

(Mejor está que estaba, pp. 852-853)

Aunque la cortina no es un lugar en sentido estricto, sí es un referente de ello pues propone la idea de ubicación de un determinado per-

palacio, en un barco o en una montaña. [...] En esta ceremonia de la alteridad los actores fingen ser otros ante un público que acepta complacido el juego de la transformación» (Rubiera, 2005, p. 26). 
sonaje, más aún cuando se toma ventaja de este decorado al convertirlo en lugar de ocultamiento.

Dicha presencia espontánea como escape de eventos fortuitos se pone de relieve asimismo en También hay duelo en las damas, en el momento en el que don Juan entra en casa de su primaViolante cargando a la desmayada Leonor. Juan indica el porqué de su entrada inesperada en casa de Violante y señala que «los precisos accidentes / no dan lugar al respeto» (Calderón, También hay duelo en las damas, p. 1210).

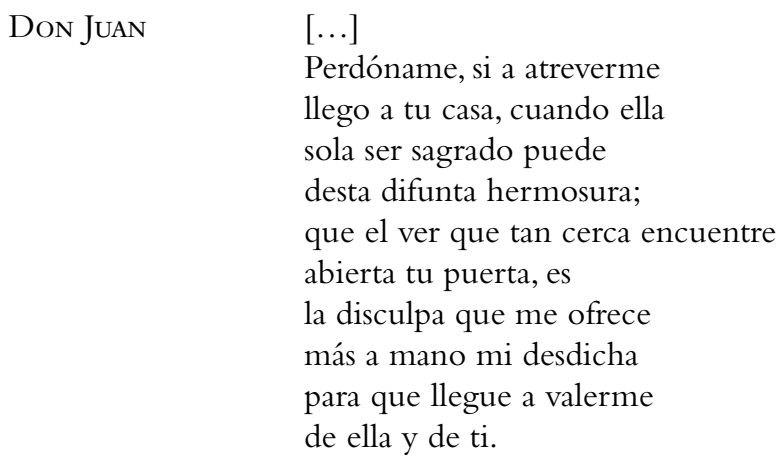

(También hay duelo en las damas, p. 1210)

La aparición de la cortina y la puerta abierta en el momento apropiado corresponde efectivamente al concepto dramático de deus ex machina y en el caso concreto de los ejemplos aludidos, sirve de apoyo para enfatizar y/o complicar el enredo.

La intervención espontánea de un espacio como propiciador de enredos puede ofrecerse también a modo de un elemento de comunicación clandestina y así se convierte en ambiente adecuado para proteger secretos. La inserción en escena de una situación azarosa e inesperada pone en peligro el resguardo de este lugar secreto, lo que propicia la tensión y el desorden entre los personajes, acciones que azuzan la gradual recepción cómica de la trama. Una muestra de esto nos la ofrece Calderón en la primera jornada de También hay duelo en las damas. El galán de doña Violante, don Félix, le hace una visita clandestina al aprovechar la ausencia de don Alonso, padre de la dama, en la morada.

Violante No has de irte.

Don Félix Cuando la puerta me cierres, me echaré por el balcón 


\begin{tabular}{|c|c|}
\hline & $\begin{array}{l}\text { de aquella cuadra de enfrente, } \\
\text { que ya sé que está sin reja. }\end{array}$ \\
\hline VIOLANTE & Tampoco es bien que aquí entres. \\
\hline DON FÉLIX & $\begin{array}{l}\text { Pues ¿qué? ¿Dos puertas me cierras, } \\
\text { cuando una ventana debes } \\
\text { abrir? }\end{array}$ \\
\hline Violante & ¿Yo abrir la ventana? \\
\hline DON FÉLIX & $\begin{array}{l}\text { Claro está, que no parece } \\
\text { bien en ninguna ocasión } \\
\text { ser las damas descorteses. } \\
\text { Y pues salir no me dejas, } \\
\text { ni entrar donde yo quisiere, } \\
\text { responde, que, ¡vive Dios!, } \\
\text { que aunque a tu padre despierte, } \\
\text { dé voces; por eso, escoge } \\
\text { lo que mejor te estuviere: } \\
\text { que salga por esa puerta, } \\
\text { por ese balcón me eche, } \\
\text { o que oiga lo que te dice. }\end{array}$ \\
\hline ViOLANTE & $\begin{array}{l}\text { (¿Qué he de hacer? ¡Cielos, valedme! } \\
\text { Si sale, a don Juan es fuerza } \\
\text { que en la calle, jay de mí!, encuentre; } \\
\text { si entra, que encuentre a su hermana; } \\
\text { si hablo que algo a entender llegue } \\
\text { contra su honor; y si a todo } \\
\text { me resisto, que despierte } \\
\text { a mi padre. }\end{array}$ \\
\hline
\end{tabular}

(También hay duelo en las damas, p. 1222)

El orden creado por los amantes para poder conversar en secreto es alterado por ruidos externos provenientes del espacio latente. Estos sonidos al trastocar dicho orden resaltan el uso dinámico de los elementos arquitectónicos, lo que se apoya también en la incorporación de la deixis demostrativa para subrayar la referencia espacial.

Espacios de distracción o despiste

Esta es una de las estrategias más usuales en la comedia cómica calderoniana. Su presencia no solo aporta un sentido cómico a la cons- 
trucción argumental, sino que también provoca la creación de enredos y en consecuencia, la fluidez de la intriga hasta el desenlace de la obra.

En La dama duende, la alacena es elemento espacial de distracción, secreto y táctica lúdica, la que favorece el encuentro clandestino y el despliegue de apariencias en escena. Este funcionamiento se basa en el trazado de un plan compartido y reconocido por sus involucrados, el cual beneficia y hace próspera la transformación de cuadros comunes y domésticos en ambientes de distracción ${ }^{16}$.

Similar tratamiento se aprecia también en El escondido y la tapada. En el transcurso de diferentes comedias de capa y espada, los escondites plantean elementos de distracción, en tanto se entienden estos como los ambientes cuya admisión revela un programa precedente. Este programa o plan premeditado acusa la intención del resguardo de un personaje, cuya entrada personifica la transgresión no solo de límites espaciales, sino también de límites simbólicos construidos para garantizar la defensa del honor familiar y de cada uno de los miembros que habitan la casa particular ${ }^{17}$.

La introducción de uno de sus ambientes como guarida en El escondido y la tapada refleja un planteamiento intencionado por parte de uno de los personajes. Es así que concretamente dos cuartos comunicados mediante una escalera secreta se convierten en herramientas de despiste.

CÉSAR

Pues

según eso, en mayor riesgo

en tu casa estoy.

Celia

¿Por qué?

CÉSAR

Porque no es posible estar un punto en ella.

Celia

Sí es;

que pueden, don César, mucho

${ }^{16}$ A raíz del vasto número de contribuciones sobre la multiplicidad y el tratamiento espacial contemplado en La dama duende (verVitse, 1996, pp. 337-356; González Pérez, 2013, pp. 163-182, entre otros) se ha preferido evitar dar mayores precisiones de esta comedia y dirigir el enfoque sobre otras.

${ }^{17}$ Estos refugios, sin embargo, en caso de no evidenciar plan premeditado alguno pueden ejemplificar el prototipo de un espacio de presencia casual. En ambos casos, su aparición es dispuesta por el dramaturgo a manera de maniobra creadora de enredos mediatos o inmediatos. 


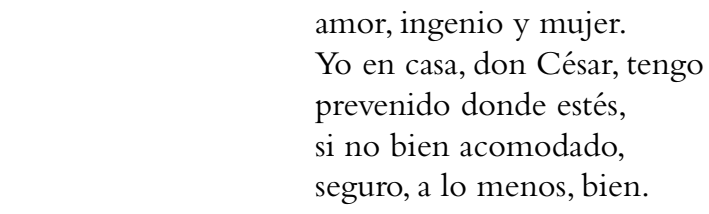

CÉSAR

¿De qué suerte?

Celia

Desta suerte.

Aquesta casa que ves, tiene dos cuartos: el bajo, $\mathrm{y}$ el alto, que es este en que yo vivo, porque en esotro vive un extranjero, a quien vienen despachos de Roma: esto convino saber, por si acaso el dueño hallaba para toda ella alquiler, por de dentro della tiene secreta escalera, que comunica los dos cuartos, aunque condenada esté, por ser los huéspedes dos.

(El escondido y la tapada, p. 683)

De este modo Celia describe a César en detalle las argucias con las que ha modificado las piezas domésticas para convertirlas temporalmente en refugio del galán.

Pero esta nueva configuración ¿de qué va a distraer? Al encontrarse un personaje escondido, cuya revelación correspondería a la aclaración del ingrediente axial de las comedias, los enredos, se mantiene la tensión entre los coprotagonistas y se sigue construyendo la intriga argumental. En el caso de los espectadores, la distracción se plasma de dos maneras: la atención se bifurca en una observación pasiva centrada en el personaje mientras se esconde, y en una activa, que dirige la mirada sobre los personajes que giran alrededor del escondrijo y del escondido, produciendo dicha interacción de movimientos la risa basada en la confusión. 


\section{Conclusiones}

La disposición espacial es una estrategia de comicidad, que al presentarse en consonancia con maniobras de múltiple calibre y oportunos apuntes temporales, es decir en armonía premeditada con determinados momentos claves, logra el regocijo inmediato o la construcción gradual del enredo en beneficio del divertimento del público. La respuesta cómica a este recorrido argumental y a la intervención espacial descansa obviamente sobre la tácita connivencia entre emisor y receptor durante la función teatral. Al sacar provecho de las «estrategias espaciales de comicidad» anteriormente desarrolladas, el dramaturgo construye ciertos ejes que propician los enredos. Su fluidez a través del argumento y el posterior desembrollo son marcados indudablemente y de manera decisiva por la mutación y la interacción espacial puesta en escena. 


\section{BibLIOGRAFÍA}

Arata, Stefano, Textos, géneros, temas: investigaciones sobre el teatro del Siglo de Oro y su pervivencia, Pisa, ETS, 2002.

Arellano, Ignacio, «Valores visuales de la palabra en el espacio escénico del Siglo de Oro», Revista Canadiense de Estudios Hispánicos, 3, 1995, pp. 411-443.

BArros, Sandro R., «¿Humor o barroquismo incongruente? La risa como mecanismo consonante en Don Quijote», Espéculo. Revista de estudios literarios, 34, 2006 (Revista en línea).

Bergson, Henri, La risa. Ensayo sobre el significado de la comicidad, Buenos Aires, Godot, 2011.

Bobes Naves, María del Carmen, Semiología de la obra dramática, Madrid, Arco/Libros, 1997.

Calderón de la Barca, Pedro, La dama duende, en Primera parte de comedias, ed. Luis Iglesias Feijoo, Madrid, Biblioteca Castro, 2006, pp. 757-858.

Calderón de la Barca, Pedro, El escondido y la tapada, en Obras completas, Comedias, II, ed. Ángel Valbuena Briones, Madrid, Aguilar, 1973.

Calderón de la Barca, Pedro, El hombre pobre todo es trazas, en Segunda parte de comedias, ed. Santiago Fernández Mosquera, Madrid, Biblioteca Castro, 2007, pp. 651-735.

Calderón de la Barca, Pedro, Mejor está que estaba, en Sexta parte de comedias, ed. José María Viña Liste, Madrid, Biblioteca Castro, 2010, pp. 847-940.

Calderón de la Barca, Pedro, También hay duelo en las damas, en Tercera parte de comedias, ed. Don W. Cruickshank, Madrid, Biblioteca Castro, 2007, pp. 1199-1328.

Cazal, Françoise, Christophe González y Marc Vitse (ed.), Homenaje a Frédéric Serralta. El espacio y sus representaciones en el teatro español del Siglo de Oro, Madrid / Frankfurt, Iberoamericana / Vervuert, 2002.

García Barrientos, José Luis, Cómo se comenta una obra de teatro, Madrid, Síntesis, 2003.

García Barrientos, José Luis, «Discurso del método», en Análisis de la dramaturgia. Nueve obras y un método, ed. José Luis García Barrientos, Madrid, Fundamentos, 2007, pp. 11-40.

GonzÁlez PÉrez, Aurelio, «Calderón y la multiplicidad espacial en comedias de capa y espada», Anuario Calderoniano, 6, 2013, pp. 163-182.

Llanos López, Rosana, «Humor inofensivo/humor tendencioso: los géneros de la (son)risa", en Memoria de la palabra. Actas del VI Congreso de la Asociación Internacional Siglo de Oro, ed. Francisco Domínguez Matito y María Luisa Lobato, Frankfurt / Madrid, Vervuert / Iberoamericana, 2004, pp. 11651176.

Llanos López, Rosana, Teoría psicocrítica de la comedia: la comedia española en el Siglo de Oro, Kassel, Reichenberger, 2005. 
Mauron, Charles, Psicocrítica del género cómico, Madrid, Arco/Libros, 1998.

Pedraza, Felipe B., Calderón. Vida y teatro, Madrid, Alianza, 2000.

Ruano de la Haza, José María, «Espacios teatrales y puesta en escena», en Calderón desde el 2000: Simposio internacional Complutense, ed. José María Díez Borque, Madrid, Ollero y Ramos, 2001, pp. 349-372.

Rubiera Fernández, Javier, La construcción del espacio en la comedia española del Siglo de Oro, Madrid, Arco/Libros, 2005.

Ruiz Ramón, Francisco, Calderón nuestro contemporáneo. El escenario imaginario. Ensayo sinóptico, Madrid, Castalia, 2000.

Sepúlveda, Jesús, «Haz y envés de convenciones en El escondido y la tapada de Pedro Calderón de la Barca», Criticón, 87-89, 2003, pp. 815-826.

VITSE, Marc, «Sobre los espacios en La dama duende: el cuarto de don Manuel», Rilce, 2, 1996, pp. 337-356. 